Iraq

\section{Iraq: time to focus our response}

\section{A Barr, J J Miranda}

D uring the preparation of this piece, the newspaper headline on that day's cover story was "52 die in Baghdad market blast ... US declines to comment". The death toll after this attack was put at 58. ${ }^{1}$ The media have provided vast coverage of the attacks so far but, in doing so, have perhaps diverted our attention away from longer term health impacts.

Over the past few months a strong and steady expression of alarm about the humanitarian consequences of conflict in Iraq has come from the medical profession. $^{23}$ The latest report on the health impacts of war in the Gulf has come from the WHO, and is a graphic illustration of the need for concern. Deterioration in public utilities, transport and health infrastructures over the past 12 years have resulted in the vulnerability of the Iraqi people being much higher now than at the start of the 1991 Gulf war. Expected mortality rate estimates range from 48000 to 261000 for just the first three months after conflict. ${ }^{2}$ The need for massive humanitarian intervention in Iraq is well established. The detail of what that humanitarian action will be is much less clear.

Lieutenant-General William Wallace, commander of US army forces in the region, told the Washington Post the present situation in Iraq was "different from the one we'd wargamed". ${ }^{5}$ While doubts over the aptness of military planning for the war are now growing, concern over humanitarian planning has always been present. NGOs have been frustrated by the lack of cooperation from US military planners, ${ }^{6}$ as the US government, through the US Agency for International Development (USAID), has developed a plan in isolation from other agencies. The appropriateness and

The authors prepared this article during the ongoing conflicts in Iraq. Since the submission and acceptance of this piece the conflict has resulted in the fall of the Ba'ath party dictatorship. However, this success does not, and must not, detract our concern from the humanitarian issues expressed in this article. These issues remain just as unresolved now as when this piece was written.

Article submitted 31 March 2003

Accepted for publication 1 April 2003

Published online 4 April 2003 adequacy of military led aid is in doubt. ${ }^{7}$ A UK House of Commons International Development Committee (IDC) report identified a lack of openness about contingency planning, and under funding of preparations for relief efforts, compared with other recent conflicts. ${ }^{8}$ The IDC concluded that "insufficient emphasis has been placed on the humanitarian implications of military action" and they were unconvinced that a viable humanitarian plan existed.

Developments since the outbreak of war have given no cause for comfort. The idea that the Oil-For-Food (OFF) programme might continue even in the event of conflict-an idea expressed by USAID - was wishful thinking. Sixty per cent of Iraqis depend on OFF programme rations to survive, and it costs $\$ 250$ million per month for the food component alone. ${ }^{8}$ This gives perspective to the $\$ 300$ million of food aid promised by the US. ${ }^{10}$ Even if USAID can sustain funding in lieu of the OFF programme, the delivery chains used by OFF are unlikely to function, partly because they are largely administered by Iraqi government officials. ${ }^{8}$ Chronic malnutrition rates in Iraqi children under the age of 5 are estimated to be over $23 \%$.

The situation now in Iraq is already a humanitarian disaster. Reports from the city of Basra indicate that more than half of the civilian population has no access to safe drinking water and no electricity. ${ }^{11}$ Dysentery and typhoid outbreaks occur in Basra even when water and electricity supply is normal. ${ }^{11}$ Relief efforts since war began have amounted only to token gestures. The British supply ship Sir Galahad, initially delayed by mines and weather, has now docked at the port of Umm Qasr. Whether distribution beyond the immediate area is possible is questionable and aid NGOs have expressed concern. ${ }^{12}$ There were desperate scenes at the southern Iraq town of Safwan on 26 March, when three truckloads of aid from the Kuwait Red Crescent Society arrived. It was an exact model of how humanitarian relief should not be enacted, and sets a worrying precedent.

Both NGOs and UN agencies are crying out for more funds to cope with what will potentially be "the largest humanitarian operation in history". ${ }^{13}$ The US administration is spending to date US\$206 million on humanitarian relief and US\$300 million on food supplies to Iraq. ${ }^{14}$ This figure is dwarfed by the US $\$ 62.6$ billion being spent by the US on its military campaign. ${ }^{15}$ Regionally and globally, peoples' health, dignity, and wellbeing are prerequisites for stability and security, yet they are peripheral concerns in this "war against terrorism".

The medical profession's input to the anti-war movement was controversial ${ }^{16}$ and ultimately ineffectual. There is now a war in Iraq and the humanitarian consequences have already begun. However, the role of the medical world is now more important than ever. Firstly, we must raise attention to the need for a proper and effective response for the Iraqi population. Secondly, pressure on all our governments to commit to effective humanitarian intervention must be increased.

$J$ Epidemiol Community Health 2003:57:395-396

\section{Authors' affiliations}

D A Barr, J J Miranda, on behalf of the International Health Advocacy Group, International Health and Medical Education Centre, University College London, London N19 5LW, UK

Correspondence to: Dr J J Miranda; j.miranda@ucl.ac.uk

\section{REFERENCES}

1 Goldenberg S. 52 die in Baghdad market blast. The Guardian 2003 Mar 29;1.

2 Medact. Collateral damage: The health and environmental costs of war on Iraq. London: Medact, 2002.

3 Stephens C, on behalf of 500 signatories of the London School of Hygiene and Tropical Medicine. Open letter to Tony Blair, Prime Minister of the UK: public health and humanitarian effects of war on Iraq. Lancet 2003;361:345.

4 World Health Organization. Potential impact of conflict on health in Iraq. Geneva: WHO; March 2003. http://www. who.int/ features/2003/iraq/briefings/ iraq_briefing_note/en/ (accessed 31 Mar 2003)

5 Atkinson R. General: a longer war likely. The Washington Post 2003 Mar 27;A0 1.

6 McCarthy M. US military plans to lead relief efforts in Iraq. Lancet 2003;361:629.

7 Oxfam International. Iraq: humanitarian-military relations. Oxfam Briefing Paper no 41; Mar 2003.

8 House of Commons International Development Committee. Preparing for the humanitarian consequences of possible military action against Iraq. Fourth Report of Session 2002-2003, Vol 1, HC 444-I. London: The Stationery Office, Mar 2003

9 US Agency for International Development USAID Contingency plans for humanitarian assistance to Iraq. USAID Fact Sheet; $24 \mathrm{Feb}$ 2003. http://www.usaid.gov/press/releases/ 2003/fs030224.html (accessed 31 Mar 2003)

10 US Agency for International Development. US Humanitarian Assistance to Iraq. USAID Fact Sheet; 25Mar 2003. http:// www.usaid.gov/press/releases/2003/ fs030325.html (accessed 31 Mar 2003)

11 World Health Organization. UN

humanitarian briefing in Amman, Jordan. Geneva: WHO, 26 Mar 2003. http://www. who. int/features/2003/iraq/ briefings/Wednesday26/en/print.html

12 BBC News. UK aid ship docks at Iraqi port. BBC News 2003 Mar 28. http:// news.bbc.co.uk/1/hi/uk/28942.stm (accessed 31 Mar 2003) 
13 World Food Programme. WFP launches US\$1.3 billion appeal for Iraq operation. WFP News Release, 28 Mar 2003

14 US Agency for International Development Food and non-food relief supplies to Iraq.
USAID Fact Sheet: 25 Mar 2003

http://www.usaid.gov/press/releases/ 2003/fs030324.html

15 White House. Supporting our troops abroad and increasing safety at home. Washington:
Office of Press Secretary, 25 Mar 2003. http:// www.whitehouse.gov/news/releases/2003/ 03/20030325.html (accessed 31 Mar 2003)

16 Coombes $\mathbf{R}$. War of words over Iraq. BM

2003;326:230.

\section{Towards legionnaires' disease control: epidemiological or environmental surveillance?}

\section{A Plasència, J A Caylà}

\section{Public health efforts need to focus on environmental risk management practices}

T he recent advances in the rapid diagnosis of legionnaire's disease and its increasing use by healthcare professionals, ${ }^{1}$ together with the development of new methods of molecular typing of Legionella pneumophila strains, ${ }^{2}$ are bringing about a whole new picture on the epidemiology of this disease. This not only includes a greater and quicker possibility of detecting outbreaks, but also enables a more specific approach to the investigation of the emission sources under suspicion. The fact that an increasing number of outbreaks are reported yearly, ${ }^{3}$ and that they seem to yield a growing number of cases, is probably related to this new situation. Moreover, many of the causal relations regarding the sources of some of the earlier investigated outbreaks might not prove to hold any more on the grounds of the new molecular typing methods.

Che and colleagues report in this issue of the journal ${ }^{5}$ an ecological association at the small area level between the presence of industrial systems with aerosol generating devices and the incidence of legionnaires' disease in France, based on the reporting of sporadic cases. Such results are overall consistent with what is increasingly known about potential sources of Legionella pneumophila, which include water cooled systems in industrial plants. Nevertheless, this finding underscores the need to examine in more depth the implications of the reporting of isolated cases of legionnaires' disease. More specifically, should the reporting of a sporadic case be enough evidence to purport a more intense epidemiological investigation, as well as specific environmental actions to prevent the occurrence of more cases and perhaps avoid potential outbreaks?
Surveillance systems are generally advised to collect epidemiological data on potential exposures for every reported legionnaires' disease case, even if sporadic. It is assumed that this information will provide clues to help in the identification of sources of contaminated water potentially involved in the occurrence of the reported case. Moreover, it is expected that the accumulation of such information throughout time can shed additional light on sources of exposure to Legionella pneumophila. Nevertheless, one must bear in mind that in most cases the identification of such sources has been made possible in outbreak episodes, while isolated cases hardly ever allow for the finding of implicated sources, especially when they occur in urban areas, with a high number of cooling towers and other aerosol producing systems. In fact, environmental investigations in response of the reporting of isolated cases often find sources of Legionella pneumophila for which laboratory results indicate that they are not causally related with the reported cases, reinforcing the saying that "whoever looks for Legionella, finds it". Thus, public health departments tend to regard quite sceptically the real usefulness of the epidemiological investigation of sporadic cases, which may be seen more or less as trying to "find the needle in a haystack". Besides, the increasing acknowledgement that "Legionella is here to stay" tends to mitigate large scale investigations of sporadic cases, while concentrating on outbreaks, which usually raise ample media and community concerns, and allow for a more feasible use of standard methods of epidemiological investigation.

Still, one could argue that the investigation of isolated cases of legionnaires' disease can be useful if it helps identifying potentially contaminating sources of Legionella, prompting cleaning and maintance actions by the owners of the systems. Nevertheless, the introduction by an increasing number of countries of strict regulations regarding risk management of cooling towers and other aerosol producing devices, which include registration, periodic sampling and testing, water treatment and occupational and safety systems, somehow questions the usefulness of traditional public health efforts to attain an effective control of the risk of legionnaires' disease through the epidemiological investigation of every reported case. Instead, it seems advisable that public health and environmental authorities reorient their efforts towards the surveillance of a strict adherence to risk management regulations by owners of water aerosol producing devices.

Although it is still early to evaluate the sustained effectiveness of such strategies, public health departments, rather than spending unfocused efforts investigating sporadic cases of legionnaires' disease, should instead use this opportunity to reinforce their capabilities in the reporting, investigation and control of large outbreaks, especially as regards the timeliness in the availability of laboratory results, the implementation of effective coordination systems with environmental authorities, as well as the adoption of comprehensive risk communication strategies.

Now that we begin to understand that Legionella can hardly be wiped out of our environment, we need to concentrate on keeping it off. While there is no doubt that good epidemiological surveillance is still needed, especially to reduce the number of undetected or late detected outbreaks, it is time for environmental surveillance activities to take the lead as the key public health measure in the control of legionnaires' disease.

$J$ Epidemiol Community Health

2003;57:396-397

\section{Authors' affiliations}

A Plasència, J A Caylà, Agència de Salut Pública de Barcelona (formerly Institut Municipal de Salut Pública, Barcelona) and Universitat Autònoma de Barcelona

Correspondence to: Dr A Plasència, Agència de Salut Pública de Barcelona, Lesseps 1, 08023 Barcelona, Spain; aplasenc@imsb.bcn.es 


\author{
REFERENCES \\ 1 Win WC Jr. Legionella. In: Baron EJ, Pfaller \\ MA, Tenover FC, et al, eds. Manual of clinical \\ microbiology. 7th edn. Washington DC: \\ American Society for Microbiology, \\ 1999:572-85. \\ 2 Valsangiacomo C, Baggi F, Gaia IA, et al. \\ Use of amplified fragment lengh \\ polymorphism in molecular typing of $\mathrm{L}$.
}

\begin{abstract}
pneumophila and application to epidemiological studies. I Clin Microbiol 1995;33:1716-19.

3 Lever F, Joseph CA, on behalf of the European Working Group for Legionella Infections (EWGLI). Travel associated legionnaires' disease in Europe in 1999 Eurosurveillance 2001;6:53-61.

4 Caylà JA, Jansà JM, Pañella $H$, et al. Investigación de brotes comunitarios de
\end{abstract}

legionelosis. Med Clín (Barc) 2002;119(suppl 2):50-5.

5 Che D, Decludt B, Campese C, et al. Sporadic cases of community acquired legionnaires' disease: an ecological study to identify new sources of contamination. $J$ Epidemiol Community Health 2003;57:466-9.

\section{Age in epidemiological analysis}

\section{S A Reijneveld}

\section{It still merits attention}

A nalyses by age are among the most widely used tools from the epidemiological toolbox. They are mostly used to adjust for confounding (as a result of age) or to assess effect modification. The epidemiologist generally handles age in two ways: as a continuous variable, or as a categorised variable by combining a number of adjacent ages into a joint category. When looking at age as a continuous variable, standard epidemiological textbooks such as Rothman and Greenland's and many others recommend registering age as precisely as possible. ${ }^{1}$ They also draw attention to the handling of age, especially to the way in which categories are chosen. Categories should not be too extensive to prevent residual confounding by age (an incomplete adjustment for age as the variation of a risk within a category is too wide). ${ }^{1}$ To stimulate comparisons of studies, the International Journal of Epidemiology even provides guidelines on forming categories: "grouping should be mid-decade to mid-decade or in five-year age groups (e.g. 35-44 or 35-39, 40-44, etc, but not 20-29, 30-39 or other groupings)." (http://ije. oupjournals.org/, assessed 7 November 2002).

Surprisingly little attention is paid, however, to two other factors regarding age that are just as relevant for epidemiological analyses. The first is whether age should be included as a continuous variable or as a categorised variable in these analyses. And, if the second option is chosen, it should be clear in which way the categories are included in the model (even when defined as indicated in the previous paragraph). Many authors include age as a single variable in their model. ${ }^{2-4}$ This may be the best option as it leads to the most parsimonious model, but only if the implicit assumption of an underlying association between the modelled outcome and age is right. For instance, if a logistic model is used, inclusion of age as a single variable implies the assumption that the logit of the outcome has a linear association with age. This is equal to the assumption that $\mathrm{p} /(1-\mathrm{p})$ (in which $\mathrm{p}$ is the proportion of observations with a given outcome) has an exponential association with age. Such an assumption may be right, depending on the outcome, but should be assessed separately. If the assumption is proved to be right age should be included as the original continuous variable. The use of categories in this case will increase measurement error and the likelihood of residual confounding. ${ }^{1}$ If the underlying assumption is not right, however, including age as a single variable in the model may lead to residual confounding or even introduce additional confounding, and thus yield biased results. In that case, a transformation of the measurement scale of age (for instance by a logarithmic transformation, or by a power transformation like a square root or a polynomial) may still yield a valid and parsimonious model (see standard statistical textbooks such as the one by Armitage et al). ${ }^{5}$ It may be a good alternative to include dummies for each age category in the model, to exclude any assumptions regarding the association of age with the outcome.

A second factor is the impact of age in analyses in which socioeconomic position is associated with health outcomes, both at the individual and at the contextual level. ${ }^{6}$ Age may be strongly associated with socioeconomic positions at both levels. Regarding socioeconomic position at the individual level, the meaning of educational level may for instance depend on the age group concerned, at least in industrialised countries. In most of these countries, educational level is strongly associated with age. Among the elderly population, having only primary education or even less is highly prevalent, whereas it is rare among young adults. Thus among young adults having only primary education is a strong indicator of deprivation. Analytically, this may result in logistic models showing a modification by age of the association of educational level with health, whereas it actually reflects the fact that the proportion of people having a lower educational level varies by age. ${ }^{7}$ Regarding socioeconomic position at the contextual level, many of its indicators are also associated with age, for instance because they are aggregates of measures of individual socioeconomic positions. In this case, the use of crude indicators of socioeconomic position may increase measurement error regarding the association between health outcomes and measures of socioeconomic position, especially if these measures are strongly associated with age (as is the case with educational level), ${ }^{8}$ and it may even introduce confounding.

In short, even though analyses by age are among the most widely used tools from epidemiological toolbox, the adequate inclusion of age still merits attention.

J Epidemiol Community Health 2003;57:397

\section{Author's affiliations}

S A Reijneveld, TNO Prevention and Health, PO Box 2215, 2301 CE Leiden, Netherlands

Correspondence to: $\operatorname{Dr} S$ A Reijneveld; sa.reijneveld@pg.tno.nl

\section{REFERENCES}

1 Rothman KJ, Greenland S, eds. Modern epidemiology. 2nd ed. Philadelphia: Lippincott-Raven, 1998.

2 Yen IH, Kaplan GA. Neighbourhood social environment and risk of death: multilevel evidence from the Alameda County Study. Am J Epidemiol 1999;149:898-907.

3 Cubbin C, LeClere FB, Smith GS. Socioeconomic status and injury mortality: individual and neighbourhood determinants. J Epidemiol Community Health 2000;54:517-24.

4 Winkleby MA, Cubbin C. Influence of individual and neighbourhood socioeconomic status on mortality among black,

Mexican-American, and white women and men in the United States. J Epidemiol Community Health 2003;57:444-52.

5 Armitage P, Berry G, Matthews JNS. Statistical methods in medical research. 4th edn. Oxford: Blackwell, 2001.

6 Diez-Roux AV. A glossary for multilevel analysis. J Epidemiol Community Health 2002;56:588-94.

7 Reijneveld SA, Gunning-Schepers LJ. Age, health and the measurement of socio-economic status of individuals. Eur J Public Health 1995;5:187-92.

8 Reijneveld SA, Gunning-Schepers L. Age, socioeconomic status, and mortality at the aggregate level. J Epidemiol Community Health 1994;48: 146-50. 